\title{
Suppressing the morning rise in cortisol impairs free recall
}

\author{
Ulrike Rimmele, ${ }^{1,2,4}$ Flurina Meier, ${ }^{1,3}$ Tanja Lange, ${ }^{1}$ and Jan Born ${ }^{1}$ \\ ${ }^{1}$ Department of Neuroendocrinology, University of Lübeck, Lüebeck 23562, Germany; ${ }^{2}$ Department of Psychology, New York \\ University, New York, New York 10003, USA; ${ }^{3}$ Institute of Human Movement Sciences and Sport, ETH Zurich CH-8092, Switzerland
}

\begin{abstract}
Elevated glucocorticoid levels impair memory retrieval. We investigated whether retrieval under naturally elevated glucocorticoid levels, i.e., during the morning rise in cortisol can be improved by suppressing cortisol. In a crossover study 16 men retrieved emotional and neutral texts and pictures (learned $3 \mathrm{~d}$ earlier) 30 min after morning awakening, following administration of the cortisol synthesis inhibitor metyrapone or placebo. Unexpectedly, the metyraponeinduced cortisol suppression significantly impaired free recall of both materials. Recognition remained unaffected. Thus, not only high, but also very low glucocorticoid levels impair retrieval, with the latter effect possibly reflecting insufficient occupation of hippocampal/amygdalar mineralocorticoid receptors (MRs).
\end{abstract}

[Supplemental material is available online at http://www.learnmem.org.]

Glucocorticoids influence memory processing in all stages, i.e., encoding, consolidation, and retrieval (de Quervain et al. 2009). The effects vary depending on the level of the hormone and on the emotionality of the memory. In particular, for the effects on encoding of new information (including subsequent consolidation), an inverted U-shaped function has been proposed, with moderate glucocorticoid concentrations enhancing these processes, but very low and very high concentrations exerting a diminishing effect (de Kloet et al. 1999; Newcomer et al. 1999; Roozendaal 2000; Abercrombie et al. 2003; Maheu et al. 2004). Compared with encoding, the effects of glucocorticoids on memory retrieval have been less well-investigated. Most studies examined retrieval under moderately elevated glucocorticoid levels induced by either administering the major glucocorticoid, i.e., cortisol in humans and corticosterone in rats, or by stress. These studies consistently showed that moderately elevated glucocorticoid levels impair memory retrieval in both rats (de Quervain et al. 1998; Roozendaal et al. 2003, 2004) and humans (de Quervain et al. 2000, 2009; Domes et al. 2004, 2005; Kuhlmann et al. 2005a,b; Buchanan et al. 2006; Buchanan and Tranel 2008). Of note, in rats the retrieval impairment associated with elevated glucocorticoid levels could be abolished by administration of the glucocorticoid synthesis inhibitor metyrapone (de Quervain et al. 1998; Roozendaal et al. 2001). Additionally, there is evidence that the glucocorticoid-induced retrieval impairment occurs specifically for emotionally arousing information (Kuhlmann et al. 2005a,b; de Quervain et al. 2007; Smeets et al. 2008; Tollenaar et al. 2009) or in emotionally arousing testing situations (Kuhlmann and Wolf 2006).

While the impairing effect of glucocorticoids on retrieval is well documented, it is presently not clear whether this adverse effect can be prevented by blocking the occurrence of elevated cortisol levels in humans. Cortisol levels are naturally not only increased during stress, but due to the circadian rhythm and an additional response to morning awakening, cortisol is also distinctly increased to stress-like levels in the morning

\footnotetext{
${ }^{4}$ Corresponding author.
}

Email ur228@nyu.edu; fax (212) 995-4349.

Article is online at http://www.learnmem.org/cgi/doi/10.1101//m.1728510. hours (Born et al. 1999; Wilhelm et al. 2007). Memory retrieval, indeed, seems to be less efficient in these morning hours compared with afternoon or evening hours, when cortisol is low (Tilley and Warren 1983; Het et al. 2005; Yang et al. 2007). Here, we took this morning rise in cortisol (combining circadian and awakening-related cortisol release) as a model to examine whether the impairing effect of elevated glucocorticoid levels on retrieval can be prevented by administration of metyrapone.

Sixteen healthy men (mean \pm SD: $22.3 \pm 3.89$ yr of age) participated in the double-blind, within-subject crossover study. (For a detailed description of methods and additional results, please see Supplemental material.) The study was approved by the local ethics committee. After an adaptation night in the laboratory, each participant was tested in two conditions (metyrapone vs. placebo), separated by an interval of at least $12 \mathrm{~d}$, with the order of conditions balanced across subjects. Each condition included a learning session and a retrieval session (Fig. 1A). In the learning session (9:00 a.m.-11:00 a.m.), participants memorized emotional and neutral texts (Wagner et al. 2005) and pictures (Lang 1999). Thereafter, as a measure of encoding level, immediate free recall was tested. In the retrieval session (7:30 a.m.-8:30 a.m.) 3d later, retrieval of the materials was assessed by a free recall and a recognition test. Retrieval testing took place following oral administration of either metyrapone ( $3 \mathrm{~g}$, Novartis Pharma) or placebo at 4:00 a.m. In pilot experiments this timing, in combination with the 3-g dose of metyrapone, had effectively suppressed the morning rise in cortisol. The dose was the same used previously by Wagner et al. (2005), and twofold higher than that used in the studies by Lupien et al. (Lupien et al. 2002a,b; Maheu et al. 2005). Adrenocortical and autonomic responses to metyrapone were assessed by repeated measures of salivary cortisol and $\alpha$-amylase levels, as well as heart rate.

Salivary cortisol at the time of retrieval testing (7:30 a.m.8:30 a.m.) was strongly increased after placebo $(0.51 \pm 0.14 \mu \mathrm{g} /$ $\mathrm{dl})$, but suppressed to very low levels after metyrapone $(0.086 \pm$ $0.007 \mu \mathrm{g} / \mathrm{dl}, P<0.001$; for effects of treatment; Fig. 1B). In the learning session before treatment, as expected, immediate recall of texts and pictures did not differ between the metyrapone and placebo conditions (all $P>0.17$ ), but generally participants recalled the emotional texts and pictures, as well as details of 
A Learning

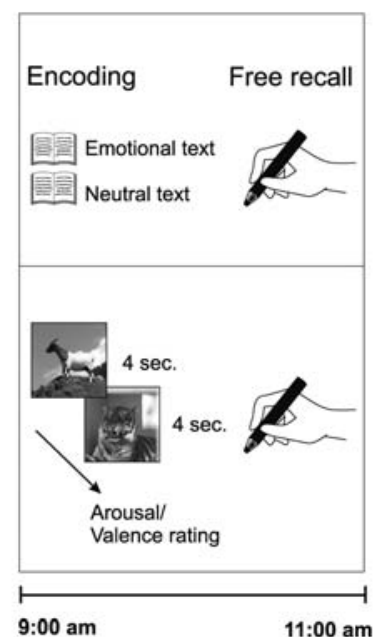

Retrieval

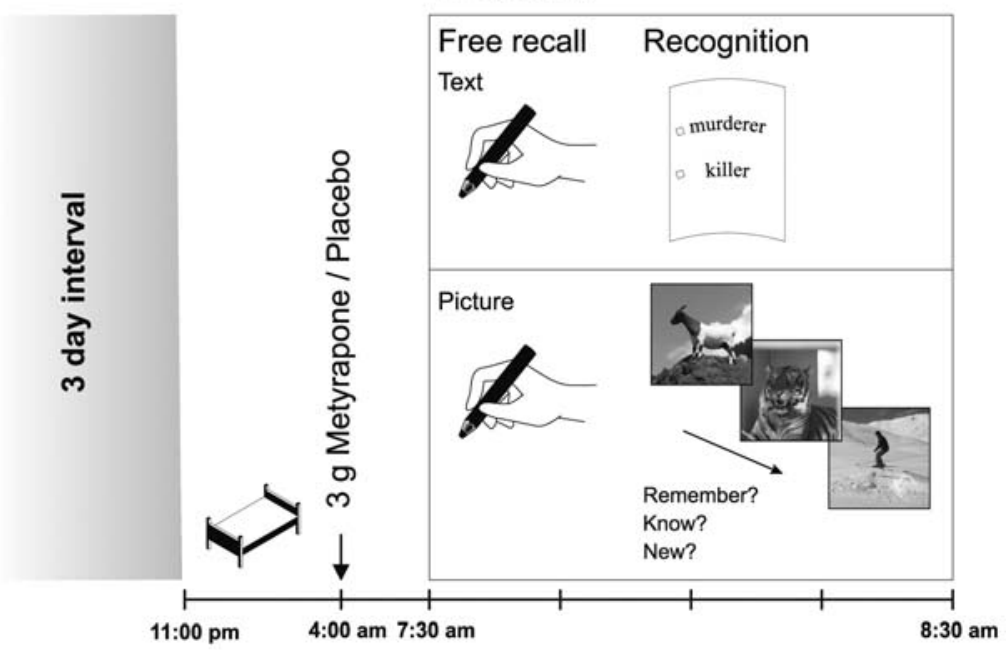

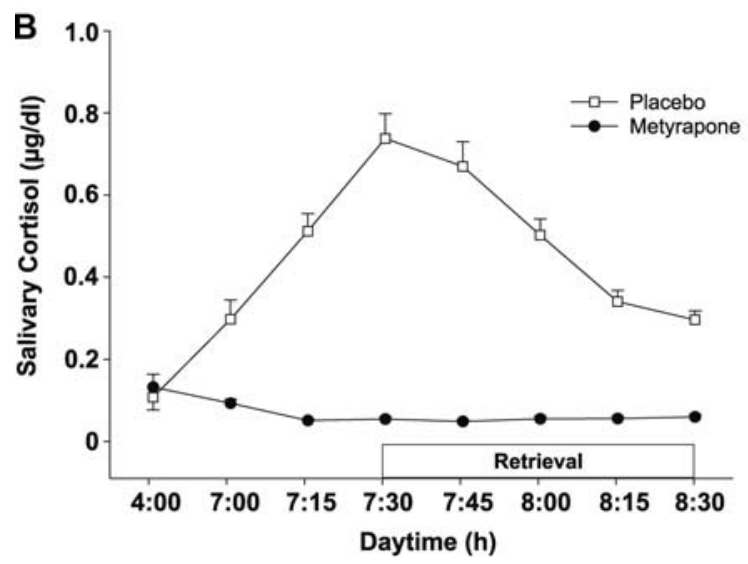

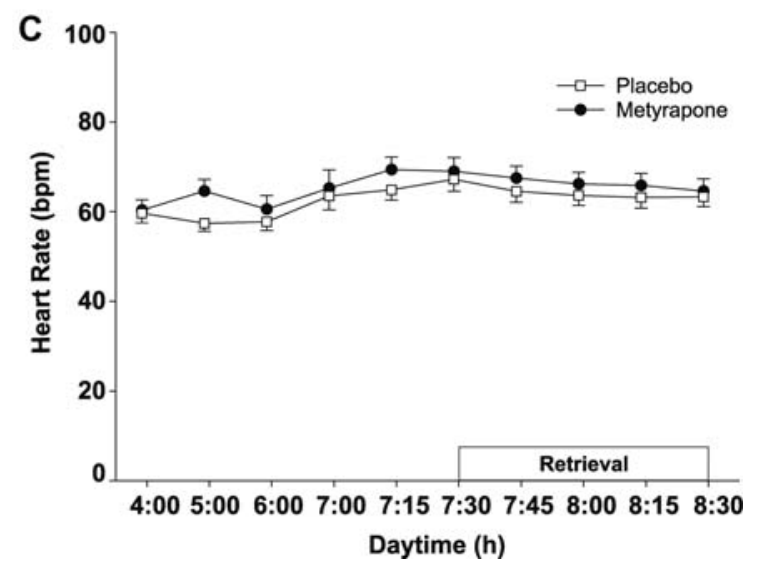

Figure 1. (A) Experimental procedure. At Learning, participants learned and immediately recalled texts and pictures of an emotional and neutral nature. Three d later, retrieval of the materials (Free recall followed by Recognition tests) was tested between 7:30 a.m. and 8:30 a.m., i.e., the time of the cortisol morning rise. Retrieval was tested after administration of either metyrapone (3 g) or placebo at 4:00 a.m. Subjects spent the night before retrieval testing in the sleep laboratory. (B) Mean \pm SEM salivary cortisol concentration at retrieval. Horizontal bar indicates time of retrieval testing. Metyrapone $(\bullet)$ completely suppressed the morning cortisol rise apparent in the placebo condition ( $\square, P<0.001$, for treatment $\times$ interaction). (C) Mean \pm SEM heart rate: Metyrapone induced a transient rise in heart rate $(P<0.01$, for comparison at 5:00 a.m. $)$, but during the time of retrieval testing, heart rate was comparable between the treatment conditions.

emotional pictures, better than the respective neutral materials $(P<0.001$ for all effects of emotionality, see Table 1 for a summary of results from the learning session).

Contrary to our expectation, administration of metyrapone before the retrieval session, compared with placebo, distinctly impaired the free recall of all memories. Metyrapone significantly diminished recall of both emotional and neutral texts (percentage of recalled content words with reference to learning performance $67.53 \% \pm 3.9 \%$ vs. $85.39 \% \pm 2.5 \%$ after placebo; $F_{(1,14)}=13.02$, $P=0.003)$, with no differential influence on emotional vs. neutral texts (treatment $\times$ emotionality $P>0.9$; Fig. 2A). This impairment was also reflected by the absolute number of content words recalled, which (collapsed across emotional and neutral texts) was $23.18 \pm 1.95$ after metyrapone and $28.56 \pm 1.96$ after placebo $\left(t_{(14)}=2.34, P<0.05\right)$. The absolute numbers of content words recalled was, as expected, higher for emotional $(32.35 \pm 1.94)$ than neutral texts $(19.35 \pm 1.94, P<0.001)$. Recognition of texts assessed after free recall did not differ between the treatment conditions ( $P>0.45$, for all comparisons; see Supplemental material).

Similar to its effect on participants' memory for texts, metyrapone also impaired memory for pictures, an effect which was most pronounced for recall of the emotional items and of picture details. The percentage (with reference to learning performance) of recalled emotional pictures was after metyrapone $(60.43 \pm$ $6.11 \%)$ and after placebo $\left(76.48 \pm 3.49 \% ; t_{(14)}=2.81, P<0.01\right)$. For the neutral pictures, a difference in the same direction failed to reach significance $(63.83 \pm 6.86$ vs. $69.19 \pm 7.77 \%, P>0.61$; $P=0.14$ for the respective treatment $\times$ emotionality interaction). Recall of picture details was also markedly impaired after metyrapone, especially for emotional pictures $\left(F_{(1,14)}=5.25, P=0.038\right.$; treatment $\times$ emotionality, $\quad F_{(1,14)}=4.05, \quad P=0.06$ treatment main effect). Subjects after metyrapone recalled only $55.31 \pm$ $5.04 \%$ of the details from emotional pictures encoded during learning, whereas after placebo, $74.75 \pm 3.82 \%$ of the details were recalled $\left(t_{(14)}=4.50, P<0.001\right)$. For the details from neutral pictures this difference was not significant $(60.02 \pm 5.16$ vs. $63.88 \pm 7.07 \%, P>0.65)$. Recognition of pictures assessed after free recall (including measures of familiarity and recollection) did not differ between the treatment conditions $(P>0.19$, for all comparisons; Fig. 2C).

The impairing effect of metyrapone on memory retrieval cannot be explained by nonspecific effects on sleep (measured 
Table 1. Memory retrieval for emotional and neutral texts under metyrapone and placebo

\begin{tabular}{|c|c|c|c|c|c|c|}
\hline & \multicolumn{2}{|c|}{ Placebo } & \multicolumn{2}{|c|}{ Metyrapone } & \multirow[b]{2}{*}{$t_{(14)}$} & \multirow[b]{2}{*}{$P$} \\
\hline & Mean & SEM & Mean & SEM & & \\
\hline \multicolumn{7}{|l|}{ Learning } \\
\hline \multicolumn{7}{|l|}{ Neutral text recall } \\
\hline Absolute no. words & 25.6 & 2.3 & 24.7 & 2.6 & 0.26 & n.s. \\
\hline $\begin{array}{l}\text { Percent of content } \\
\text { words }\end{array}$ & 27.8 & 2.5 & 27.5 & 3.0 & 0.07 & n.s. \\
\hline \multicolumn{7}{|l|}{ Emotional text recall } \\
\hline Absolute no. words & 40.4 & 2.1 & 41.6 & 2.7 & 0.35 & n.s. \\
\hline $\begin{array}{l}\text { Percent of content } \\
\text { words }\end{array}$ & 42.8 & 2.3 & 44.0 & 2.9 & 0.33 & n.s. \\
\hline \multicolumn{7}{|l|}{ Retrieval } \\
\hline Neutral text recall & 21.3 & 2.4 & 17.40 & 2.7 & 1.14 & n.s. \\
\hline Emotional text recall & 35.8 & 2.3 & 29.0 & 1.9 & 1.89 & 0.07 \\
\hline \multicolumn{7}{|l|}{ Retention } \\
\hline $\begin{array}{l}\text { Neutral text (percent } \\
\text { of learning) }\end{array}$ & 81.7 & 3.35 & 64.2 & 5.93 & 2.43 & $0.02^{\mathrm{a}}$ \\
\hline $\begin{array}{l}\text { Emotional text } \\
\text { (percent of learning) }\end{array}$ & 88.9 & 3.33 & 70.8 & 3.53 & 4.00 & $0.001^{\mathrm{a}}$ \\
\hline
\end{tabular}

${ }^{\mathrm{a}} P<0.05$ significant differences between metyrapone and placebo in memory measures.

Text recall at learning and retrieval (absolute number of content words, for learning additionally percent values with reference to total number of content words is given). Retention refers to the change from learning to retrieval. Retention of neutral and emotional texts is given in percent values in relation to learning performance. Metyrapone significantly decreased retention of both emotional and neutral texts ( $P=0.003$, for main effect of treatment). Right two columns indicate results from pairwise statistical comparisons.

by polysomnography), arousal, mood, and attention. Signs of a lightening of sleep after metyrapone, specifically a suppression of REM sleep (averaging $29.1 \mathrm{~min}, P<0.01$ ), were restricted to the 2.5-h interval after substance administration, whereas sleep before (i.e., 11:00 p.m.-4 a.m.) was well comparable between the conditions. Also, the reported sleep quality for the total night was not different between conditions $(P>0.30)$. Metyrapone also produced a temporary increase in heart rate between 4:00 a.m. and 7:00 a.m. (62.79 \pm 2.56 vs. $57.45 \pm 1.80 \mathrm{~b} / \mathrm{min}$ following placebo, $P<0.01$, Fig. 1C) but, during the time of retrieval testing, heart rate as well as salivary $\alpha$-amylase levels were closely comparable between conditions (heart rate: all $P>0.14$, Fig. 1C; average salivary $\alpha$-amylase: metyrapone: $89.80 \pm 24.78 \mathrm{U} / \mathrm{mL}$, placebo: $65.23 \pm 15.40 \mathrm{U} / \mathrm{mL} ; P>0.24)$. Changes in self-reported mood (assessed by the PANAS) were likewise negligible, with only a marginal increase in negative affect after metyrapone vs. placebo $(13.33 \pm 0.92$ vs. $12.27 \pm 0.80, P=0.084, P>0.17$ for all other measures). It could be also argued that the morning rise in cortisol affects memory function nonspecifically by enhancing attentional capacities. Attention was found to be impaired in Addison patients with chronically low cortisol levels (Klement et al. 2009) and in healthy humans after blocking mineralocorticoid receptors (MRs) with spironolactone (Otte et al. 2007). For this reason, as a control, we assessed attention by a letter cancellation test, which indeed revealed a distinctly diminished performance after metyrapone (correctly cancelled letters minus false alarms $418.53 \pm 23.00$ vs. $524.30 \pm 23.90$ after placebo; $P<$ $0.001)$. However, additional statistical analyses showed virtually no correlation between the metyrapone-induced changes in attention and memory performance $(r=0.03 ; P>0.90)$. Also, a comparison of (mediansplit-half) groups of subjects with strong vs. no or weak changes in attention performance after metyrapone did not reveal any significant association with retrieval performance (all $P>0.20$ ), overall excluding that impaired retrieval after metyrapone is sufficiently explained by a decrement of attention. Finally, it is also unlikely that the observed retrieval impairment is mediated by pituitary ACTH or/and hypothalamic CRH, whose release is enhanced after metyrapone-induced suppression of cortisol. Generally, these two hormones appear to exert only minor effects on retrieval functions and, if at all, these are toward enhancing retrieval efficiency (Born et al. 1986; Kumar and Karanth 1995; Ohmura et al. 2008).

Our study is the first to specifically examine the impact of suppressed cortisol levels on retrieval in humans. The central finding is that the suppression of the morning cortisol rise impaired free recall of emotional and neutral texts and pictures while leaving recognition unaffected. An impairing effect of metyrapone on retrieval has previously been suggested by several human studies (Lupien et al. 2002a,b; Maheu et al. 2005). However, the design of those studies did not allow to dissociate effects on retrieval from effects on encoding or consolidation, because metyrapone was effective during both learning and recall of word lists or a short story. In the present study, metyrapone was administered specifically prior to retrieval testing, eliminating any possible effects on encoding and consolidation, because learning took place $3 \mathrm{~d}$ before and was closely comparable in both treatment conditions.

The finding of impaired retrieval after suppression of cortisol contrasts with the well-documented impairment of retrieval in conditions of elevated glucocorticoid levels (de Quervain et al. 2009; Schwabe et al. 2009). Interestingly, in rats the administration of metyrapone prior to retrieval did not only distinctly decrease circulating corticosterone levels, but in parallel, blocked the glucocorticoid-induced retrieval impairment (de Quervain et al. 1998). At first glance, this finding is at odds with the present study, where metyrapone-suppressed cortisol levels were associated with impaired rather than improved retrieval performance. However, the dose of metyrapone administered in the rat study was such that circulating corticosterone was at an intermediate level, whereas in the present study metyrapone almost completely suppressed cortisol levels, leading to levels close to and even below the assay 
sensitivity during the period of retrieval testing. Taken together, these findings indeed support the previously proposed notion (Lupien and Lepage 2001; Domes et al. 2005) that the influence of circulating glucocorticoid levels follows an inverted-U shaped function, where retrieval is not only impaired under high cortisol levels, but also under extremely low levels (as reached in the present experiments).

This inverted U-shaped relationship may basically originate from differential contributions of MRs and glucocorticoid receptors (GRs) to retrieval processes. MRs bind cortisol with distinctly higher affinity than GRs, resulting in abundant MR occupation even during the circadian nadir of cortisol. In contrast, GRs become increasingly activated only after MRs are saturated to a great extent (Reul and de Kloet 1985; Joels and de Kloet 1994; de Kloet et al. 2005). Considering the minimal cortisol levels after metyrapone in our subjects, the retrieval impairment is likely to reflect a consequence of insufficient MR occupation after metyrapone. Unlike GRs, which are widely expressed in the brain, MRs are predominantly expressed in hippocampal and amygdalar regions, where they can mediate actions on neuronal activity virtually opposite those of GRs (Reul and de Kloet 1985; Korz and Frey 2003; de Kloet et al. 2005). Thus, impaired retrieval cannot only be a consequence of insufficient activation of hippocampal MRs, but likewise a consequence of predominant GR activation induced, for example, by administration of glucocorticoids. Of note, the circadian rise in glucocorticoid level, used here as a condition of elevated cortisol, is accompanied by an enhancement (by 65\%) in numbers of MRs, a relation that is not seen during stress-induced elevations of glucocorticoid levels (Reul et al. 1987). Blocking the morning rise in cortisol by metyrapone might therefore be particularly effective in increasing the proportion of unoccupied MRs and, consequently, in demonstrating the dependence of retrieval on MR occupation.

Although GR-related contributions to the retrieval deficit after metyrapone (arising from insufficient occupation of GRs) cannot be excluded (Oitzl and de Kloet 1992), a primary role for MRs in mediating retrieval deficits after metyrapone would also be consistent with the failure of metyrapone to affect recognition. Previous studies indicated that recognition memory is also spared from the impairing effects of elevated cortisol levels (de Quervain et al. 2000, 2003; Buchanan et al. 2006). Free recall and recognition involve different brain systems. Whereas free recall critically relies on the prefrontal cortex and hippocampus, and therefore is probably most sensitive to disturbing influences mediated via MRs located at high density in hippocampal networks, hippocampal contributions to recognition performance are less essential (Mayes et al. 2002; Holdstock et al. 2005). Along this line of reasoning, the overall stronger retrieval impairment for emotional rather than neutral pictures could be likewise linked to the particularly high density of MRs in the amygdala, a region critically involved in the retrieval of emotional memories (Buchanan 2007).

To summarize, the present study has uniquely shown that metyrapone administration and subsequent suppression of the morning cortisol rise impairs free recall. Combined with previous studies, which indicate an impairing effect of elevated cortisol levels on retrieval, our findings are in line with the view that the dependence of memory retrieval on circulating cortisol follows an inverted U-shaped function, and suggest that the retrieval impairment occurring at minimum cortisol concentrations (after metyrapone) results from an insufficient occupation of hippocampal and amygdalar MRs.

\section{Acknowledgments}

This research is supported by grants from the Deutsche Forschungsgemeinschaft DFG (RI 1894/2-1 and SFB 654) and from the Swiss National Science Foundation (PBZH1-118850, to U.R.). We thank Martina Kaelin and Susanne Diekelmann for help with data acquisition.

\section{References}

Abercrombie HC, Kalin NH, Thurow ME, Rosenkranz MA, Davidson RJ. 2003. Cortisol variation in humans affects memory for emotionally laden and neutral information. Behav Neurosci 117: 505-516.

Born J, Fehm HL, Voigt KH. 1986. ACTH and attention in humans: A review. Neuropsychobiology 15: 165-186.

Born J, Hansen K, Marshall L, Molle M, Fehm HL. 1999. Timing the end of nocturnal sleep. Nature 397: 29-30.

Buchanan TW. 2007. Retrieval of emotional memories. Psychol Bull 133: $761-779$.

Buchanan TW, Tranel D. 2008. Stress and emotional memory retrieval: Effects of sex and cortisol response. Neurobiol Learn Mem 89: 134-141.

Buchanan TW, Tranel D, Adolphs R. 2006. Impaired memory retrieval correlates with individual differences in cortisol response but not autonomic response. Learn Mem 13: 382-387.

de Kloet ER, Joels M, Holsboer F. 2005. Stress and the brain: From adaptation to disease. Nat Rev Neurosci 6: 463-475.

de Kloet ER, Oitzl MS, Joels M. 1999. Stress and cognition: Are corticosteroids good or bad guys? Trends Neurosci 22: 422-426.

de Quervain DJ, Roozendaal B, McGaugh JL. 1998. Stress and glucocorticoids impair retrieval of long-term spatial memory. Nature 394: $787-790$.

de Quervain DJ, Roozendaal B, Nitsch RM, McGaugh JL, Hock C. 2000. Acute cortisone administration impairs retrieval of long-term declarative memory in humans. Nat Neurosci 3: 313-314.

de Quervain DJ, Henke K, Aerni A, Treyer V, McGaugh JL, Berthold T, Nitsch RM, Buck A, Roozendaal B, Hock C. 2003. Glucocorticoidinduced impairment of declarative memory retrieval is associated with reduced blood flow in the medial temporal lobe. Eur J Neurosci 17: 1296-1302.

de Quervain DJ, Aerni A, Roozendaal B. 2007. Preventive effect of $\beta$-adrenoceptor blockade on glucocorticoid-induced memory retrieval deficits. Am J Psychiatry 164: 967-969.

de Quervain DJ, Aerni A, Schelling G, Roozendaal B. 2009. Glucocorticoids and the regulation of memory in health and disease. Front Neuroendocrinol 30: 358-370.

Domes G, Heinrichs M, Rimmele U, Reichwald U, Hautzinger M. 2004. Acute stress impairs recognition for positive words-association with stress-induced cortisol secretion. Stress 7: 173-181.

Domes G, Rothfischer J, Reichwald U, Hautzinger M. 2005. Inverted-U function between salivary cortisol and retrieval of verbal memory after hydrocortisone treatment. Behav Neurosci 119: 512-517.

Het S, Ramlow G, Wolf OT. 2005. A meta-analytic review of the effects of acute cortisol administration on human memory. Psychoneuroendocrinology 30: 771-784.

Holdstock JS, Mayes AR, Gong QY, Roberts N, Kapur N. 2005. Item recognition is less impaired than recall and associative recognition in a patient with selective hippocampal damage. Hippocampus 15: 203-215.

Joels M, de Kloet ER. 1994. Mineralocorticoid and glucocorticoid receptors in the brain. Implications for ion permeability and transmitter systems. Prog Neurobiol 43: 1-36.

Klement J, Hubold C, Hallschmid M, Loeck C, Oltmanns KM, Lehnert H, Born J, Peters A. 2009. Effects of glucose infusion on neuroendocrine and cognitive parameters in Addison disease. Metabolism 58: $1825-1831$.

Korz V, Frey JU. 2003. Stress-related modulation of hippocampal long-term potentiation in rats: Involvement of adrenal steroid receptors. J Neurosci 23: $7281-7287$.

Kuhlmann S, Wolf OT. 2006. A non-arousing test situation abolishes the impairing effects of cortisol on delayed memory retrieval in healthy women. Neurosci Lett 399: 268-272.

Kuhlmann S, Kirschbaum C, Wolf OT. 2005a. Effects of oral cortisol treatment in healthy young women on memory retrieval of negative and neutral words. Neurobiol Learn Mem 83: 158-162.

Kuhlmann S, Piel M, Wolf OT. 2005b. Impaired memory retrieval after psychosocial stress in healthy young men. J Neurosci 25: 2977-2982.

Kumar KB, Karanth KS. 1995. Effects of ACTH and ACTH 4-10 on aversive memory retrieval in rats. J Neural Transm Gen Sect 10: 223-229.

Lang P. 1999. International affective picture system (IAPS): Instruction manual and affective ratings. Technical Report A-4, The Center for Research in Psychophysiology, University of Florida, Gainesville, FL.

Lupien SJ, Lepage M. 2001. Stress, memory, and the hippocampus: Can't live with it, can't live without it. Behav Brain Res 127: 137-158.

Lupien S, Wilkinson CW, Briere S, Ying Kin MKN, Meaney MJ, Nair NP. $2002 \mathrm{a}$. Acute modulation of aged human memory by pharmacological 
manipulation of glucocorticoids. J Clin Endocrinol Metab 87: 3798-3807.

Lupien SJ, Wilkinson CW, Briere S, Menard C, Ng Ying Kin NM, Nair NP.

2002b. The modulatory effects of corticosteroids on cognition: Studies in young human populations. Psychoneuroendocrinology 27: 401-416.

Maheu FS, Joober R, Beaulieu S, Lupien SJ. 2004. Differential effects of adrenergic and corticosteroid hormonal systems on human short- and long-term declarative memory for emotionally arousing material. Behav Neurosci 118: 420-428.

Maheu FS, Joober R, Lupien SJ. 2005. Declarative memory after stress in humans: Differential involvement of the $\beta$-adrenergic and corticosteroid systems. J Clin Endocrinol Metab 90: 1697-1704.

Mayes AR, Holdstock JS, Isaac CL, Hunkin NM, Roberts N. 2002. Relative sparing of item recognition memory in a patient with adult-onset damage limited to the hippocampus. Hippocampus 12: 325-340.

Newcomer JW, Selke G, Melson AK, Hershey T, Craft S, Richards K, Alderson AL. 1999. Decreased memory performance in healthy humans induced by stress-level cortisol treatment. Arch Gen Psychiatry 56: $527-533$.

Ohmura Y, Yamaguchi T, Izumi T, Matsumoto M, Yoshioka M. 2008. Corticotropin releasing factor in the median raphe nucleus is involved in the retrieval of fear memory in rats. Eur J Pharmacol 584: 357-360.

Oitzl MS, de Kloet ER. 1992. Selective corticosteroid antagonists modulate specific aspects of spatial orientation learning. Behav Neurosci 106: $62-71$.

Otte C, Moritz S, Yassouridis A, Koop M, Madrischewski AM, Wiedemann K, Kellner M. 2007. Blockade of the mineralocorticoid receptor in healthy men: Effects on experimentally induced panic symptoms, stress hormones, and cognition. Neuropsychopharmacology 32: $232-238$.

Reul J, de Kloet ER. 1985. Two receptor systems for corticosterone in the rat brain: Microdistribution and differential occupation. Endocrinology 117: $2505-2511$.

Reul JM, van den Bosch FR, de Kloet ER. 1987. Differential response of type I and type II corticosteroid receptors to changes in plasma steroid level and circadian rhythmicity. Neuroendocrinology 45: $407-412$.
Roozendaal B. 2000. 1999 Curt P. Richter award. Glucocorticoids and the regulation of memory consolidation. Psychoneuroendocrinology 25: 213-238.

Roozendaal B, Phillips RG, Power AE, Brooke SM, Sapolsky RM, McGaugh JL. 2001. Memory retrieval impairment induced by hippocampal CA3 lesions is blocked by adrenocortical suppression. Nat Neurosci 4: 1169-1171.

Roozendaal B, Griffith QK, Buranday J, De Quervain DJ, McGaugh JL. 2003. The hippocampus mediates glucocorticoid-induced impairment of spatial memory retrieval: Dependence on the basolateral amygdala. Proc Natl Acad Sci 100: 1328-1333.

Roozendaal B, Hahn EL, Nathan SV, de Quervain DJ, McGaugh JL. 2004. Glucocorticoid effects on memory retrieval require concurrent noradrenergic activity in the hippocampus and basolateral amygdala. I Neurosci 24: 8161-8169.

Schwabe L, Wolf OT, Oitzl MS. 2009. Memory formation under stress: Quantity and quality. Neurosci Biobehav Rev 34: 575-583.

Smeets T, Otgaar H, Candel I, Wolf OT. 2008. True or false? Memory is differentially affected by stress-induced cortisol elevations and sympathetic activity at consolidation and retrieval. Psychoneuroendocrinology 33: 1378-1386.

Tilley A, Warren P. 1983. Retrieval from semantic memory at different times of day. J Exp Psychol Learn Mem Cogn 9: 718-724.

Tollenaar MS, Elzinga BM, Spinhoven P, Everaerd W. 2009. Immediate and prolonged effects of cortisol, but not propranolol, on memory retrieval in healthy young men. Neurobiol Learn Mem 91: $23-31$.

Wagner U, Degirmenci M, Drosopoulos S, Perras B, Born J. 2005. Effects of cortisol suppression on sleep-associated consolidation of neutral and emotional memory. Biol Psychiatry 58: 885-893.

Wilhelm I, Born J, Kudielka BM, Schlotz W, Wust S. 2007. Is the cortisol awakening rise a response to awakening? Psychoneuroendocrinology 32: $358-366$.

Yang L, Hasher L, Wilson DE. 2007. Synchrony effects in automatic and controlled retrieval. Psychon Bull Rev 14: 51-56.

Received December 17, 2009; accepted in revised form January 27, 2010. 


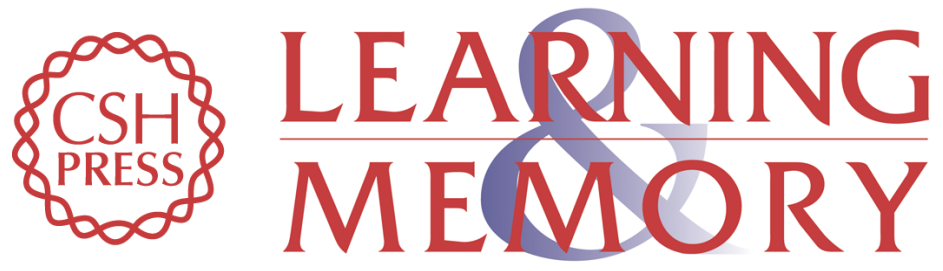

\section{Suppressing the morning rise in cortisol impairs free recall}

Ulrike Rimmele, Flurina Meier, Tanja Lange, et al.

Learn. Mem. 2010, 17:

Access the most recent version at doi:10.1101//m.1728510

Supplemental http://learnmem.cshlp.org/content/suppl/2010/03/29/17.4.186.DC1

References This article cites 47 articles, 5 of which can be accessed free at: http://learnmem.cshlp.org/content/17/4/186.full.html\#ref-list-1

License

Email Alerting Receive free email alerts when new articles cite this article - sign up in the box at the Service top right corner of the article or click here. 